\title{
Sobre historia de las ideas fónicas en España: el caso de la Ortopeia Universal de González de Valdés (1785)
}

\author{
Carmen Quijada Van den Berghe \\ Universidad de Salamanca, España
}

\begin{abstract}
Resumen
Este trabajo pretende arrojar algo de luz sobre un capítulo no excesivamente estudiado de la historia de la fonética española, las obras misceláneas del siglo XVIII, a través de la figura de Juan Antonio González de Valdés y su Ortopeia Universal (1785). El objetivo es triple: (i) ubicar el texto en la tradición ortológica española, (ii) constatar y argumentar el comienzo de un nuevo género de obras en España, que conjuga los elementos ortológicos particulares con aquellos procedentes de la fonética general, y (iii) analizar la vinculación de la Ortopeia con otras muestras de diferentes corrientes europeas, en concreto, indagar en su deuda con el Traité de la formation méchanique des langues de De Brosses (1765).
\end{abstract}

Palabras clave: ortología, pronunciación, fonética general, letra, sonido, ajustes articulatorios y acústicos.

* Para correspondencia, dirigirse a: Carmen Quijada Van den Berghe (carmenq@usal. es), Departamento de Lengua Española, Universidad de Salamanca. Plaza Anaya s/n. 37008. Salamanca (España), Tfl. +34 923294445 (ext. 1767). 


\section{On the History of Phonic Ideas in Spain: the Case of GonzÁlez de VAldÉs' Ortopeia UnIVERSAL (1785)}

This paper intends to throw some light on a chapter not too studied in the history of Spanish Phonetics, the miscellaneous works from the 18th century, through the personality of Juan Antonio González de Valdés and his Ortopeia Universal (1785). We pursue three objectives: (i) place this text in the Spanish orthoepist tradition, (ii) discuss the beginning of a new kind of works in Spain that combines orthoepic data of particular languages with notions of general Phonetics, and (iii) analyze the connections between the Ortopeia and samples of other European traditions, specifically De Brosses' Traité de la formation méchanique des langues (1765).

Keywords: Ortology, pronunciation, general Phonetics, letter, sound, articulatoy and acoustic settings.

Recibido: 17/03/15 Aceptado: 16/08/15

\section{INTRODUCCIÓN}

En la última revisión que realizó Koerner de su decisivo artículo sobre el estado de la cuestión en historia de la fonética (1995), adjuntaba una amplia bibliografía de la literatura especializada, centrada casi exclusivamente en las tradiciones lingüísticas anglosajona, germana, italiana, sueca y eslava; tampoco estaba presente el ámbito hispánico en el volumen colectivo Towards a History of Phonetics, editado por especialistas de la Universidad de Edimburgo en 1981.

Aunque se trata de una disciplina relativamente joven para nuestra tradición ${ }^{1}$, puede afirmarse que una retrospectiva realizada hoy en día, veinte años después del state-of-the-art de Koerner, contaría ya con un grupo de especialistas y estudios sobre los inicios ("protofonética") y la institucionalización de la disciplina en España. Precisamente, algunas de

\footnotetext{
Ello si se exceptúan los trabajos sobre autores de los Siglos de Oro (gramáticos y ortógrafos) realizados desde la perspectiva de la fonética histórica, y de personalidades aisladas como Bonet o Hervás y Panduro (cfr. los datos que propone Battaner en "La investigación sobre ortografía, fonética y fonología en la tradición lingüística española", 2009a).
} 
las cuestiones o periodos más desatendidos por los investigadores, según Battaner (2009a), están siendo profundizados en los últimos años: siglo XIX, métrica, sordomudística y obras heterodoxas del siglo XVIII.

En las páginas siguientes nos ocuparemos de una de estas "obras heterodoxas" del periodo ilustrado, la Ortopeia universal o Arte de pronunciar (1785) del profesor de latinidad Juan Antonio González de Valdés. Más conocido por su producción gramatical latino-castellana, su obra fónica ha quedado hasta la fecha bajo la sombra de la del ortólogo Mariano José Sicilia (Lecciones elementales de ortología y prosodia [18271828] 1832, muy difundida en los siglos XIX y XX). Como se demostró en Quijada 2014, a pesar de su escaso eco en la crítica y desconocida su divulgación posterior, la Ortopeia se postula como una pieza clave en la producción del autor a tenor de la alta consideración que él mismo le concede. En el estudio recién mencionado mostramos cómo se encaja en su sistema docente y argumentamos que la Ortopeia es un volumen dirigido al maestro -o "phonascos"- para formarlo en cuestiones fónicas generales y en la ortología de varias lenguas; es decir, la obra recoge las nociones teóricas que deben conocer como paso previo antes de iniciar a los niños en la lectoescritura. En última instancia, la perspectiva de González de Valdés es un retorno a la concepción original de la disciplina ortoépica que los actores y retóricos grecolatinos habían desarrollado inicialmente. Buen conocedor de la tradición clásica, traduce a Quintiliano y cita a Plutarco, Sciopio, Macrobio, Varrón, Gelio y a Cicerón, entre otras autoridades ${ }^{2}$. A partir del Renacimiento comienzan a aparecer ortologías sobre la correcta pronunciación latina en distintos países europeos y en esta línea contra la degradación de la pronunciación vernácula ha de insertarse nuestra obra.

Así pues, este texto tiene una motivación claramente didáctica. De hecho, González de Valdés reivindica en más de una ocasión la profesionalización e importancia de la enseñanza de la pronunciación en las primeras etapas, al igual que había hecho en 1619 uno de los autores en los que se inspira, Miguel Sebastián (profesor aragonés que compone un texto sobre lectoescritura,

2 El resurgimiento de la elocuencia/ortoepía en el periodo ilustrado es destacado por Wollock (1997: 360): "Since ancient times, actors and rhetoritians had trained the voice and speech in what was called orthoepy, or correct pronunciation and delivery, through non-medical means. These pedagogical methods were propelled by a new emphasis on eloquence, as seen, for example, in the 18 th-century British Elocutionary Movement, which had its counterpart in many other countries. At the core of this pedagogical emphasis was the formative influence of Quintilian's Institutiones Oratoriae". 
cuyo título ya distingue la parte ortológica y que será reivindicado por varios autores dieciochescos):

Este es el punto, en que los padres curiosos, deven poner cuidado, en componerle, y formarle bien la boca, y la lengua, en darle buena forma, de lengua, a su infantico. I con ninguna cosa lo puede hazer tan bien; como con cartilla, hecha con buena arte, y methodo, y maestro: que el la sepa, y tenga buena forma de lengua: y la sepa enseñar muy bien (Sebastián, Orthographia y orthologia 1619: prólogo).

Sin embargo, a pesar de su razón de ser pedagógica y de incluir algunos comentarios correctivos, González de Valdés no comparte la visión exclusivamente normativa de la disciplina que tiene Sebastián. Se impone su curiosidad descriptiva por sonidos no estándar y por los mecanismos generales de fonación y articulación. Es ahí donde entran en juego los conocimientos y avances de la época sobre la emisión de voz y propiedades fisioacústicas de los sonidos. En este momento se aleja del género ortológico al uso para adoptar una perspectiva holística donde caben, además, formulaciones sobre fonética general procedentes de la tradición ilustrada francesa. Creemos, por dicho motivo, que se trata de una obra de corte nuevo en la tradición hispánica y trataremos de argumentarlo en los siguientes apartados.

\section{GONZÁLEZ DE VALDÉS. ALGUNOS DATOS BIO-BIBLIOGRÁFICOS}

Según los datos proporcionados por Gómez Asencio (2009 [1996]: 551-552) y García Folgado (2005: 183-184), Juan Antonio González de Valdés nace en 1729 en Carcedo (Asturias). En 1757 se traslada a Madrid y comienza su enseñanza del latín en diferentes escuelas (en los Reales Estudios de San Isidro o en la Academia latina matritense, que dirige durante un periodo). En 1779, año de publicación de su primera obra, se sabe que posee su propia escuela en la Plazuela de Santo Domingo. Continúa la enseñanza de la lectoescritura y de la gramática latina y castellana a jóvenes nobles hasta su fallecimiento, posiblemente algo después de 1798, cuando publica la segunda edición revisada de su Gramática completa grecolatina y castellana. Así pues, la obra de González de Valdés tiene una marcada orientación propedéutica destinada en última instancia al conocimiento de la lengua 
latina, principio escolar que goza de especial vigencia durante el último tercio del siglo XVIII (Gómez Asencio 2004 y García Folgado 2005).

Según su consideración lingüística, "el arte de hablar bien" se divide en gramática elemental (nivel fónico) y sublime (nivel morfosintáctico). Antes de iniciarse en los estudios más complejos, el estudiante debe adquirir y manejar con soltura las destrezas básicas (lectoescritura). De acuerdo con esta concepción, su producción se desarrolla cronológicamente en dos etapas y de la siguiente manera:

\begin{tabular}{|c|c|}
\hline OBRAS DE LECTOESCRITURA & OBRAS GRAMATICALES \\
\hline $\begin{array}{l}\text { - 1779. Silabario teórico-práctico } \\
\text { dividido en tres listas [lengua española]. } \\
\text { Madrid: Joaquín Ibarra. } \\
\text { - 1779. Silabario teórico-práctico } \\
\text { dividido en tres listas [lengua latina]. } \\
\text { Madrid: Joaquín Ibarra. } \\
\text { - 1785. Ortopeia universal o Arte de } \\
\text { pronunciar. Madrid: Joaquín Ibarra. } \\
\text { - 1785. Silabario trilingüe para aprender } \\
\text { á leery escribir todos los sonidos simples } \\
\text { elementales de la lengua Española, } \\
\text { Griega, y Latina. Madrid: Imprenta Real. } \\
\text { - 1785. Verdadero método de enseñar } \\
\text { a leer y a escribir los sonidos simples } \\
\text { y complexos, explicado brevemente en } \\
\text { verso. Madrid: Imprenta Real. } \\
\text { - 1785. Problema resuelto en favor } \\
\text { del mejor método de enseñar á leer en } \\
\text { todas las lenguas, defendido con autores } \\
\text { griegos, latinos, españoles, y franceses. } \\
\text { Madrid: Joaquín Ibarra. }\end{array}$ & $\begin{array}{l}\text { - 1791. Gramática de la lengua latina y } \\
\text { castellana. Madrid: Imprenta Real. } \\
\text { - 1798. Gramática completa grecolatina } \\
\text { y castellana. Segunda impresion } \\
\text { reformada y reducida, con un extracto } \\
\text { de retórica y poética. Madrid: Imprenta } \\
\text { Real. }\end{array}$ \\
\hline
\end{tabular}

Tabla 1. Producción lingüística de González de Valdés

Como se puede comprobar ya desde un punto de vista cuantitativo, nuestro autor concede verdadera importancia a la didáctica de la lectoescritura. Posiblemente sea la parcela con la que se inicie en su profesión, por lo que deja para más adelante la preparación de textos de mayor complejidad doctrinal. No obstante, han sido estas últimas obras las que han interesado a la mayor parte de los especialistas (Lázaro Carreter 1985[1949], Gómez 
Asencio 1981 y 1985, Zamorano 2004 o García Folgado 2005, entre otros que incluyen en sus corpus las gramáticas de González de Valdés). Del aspecto ortográfico, Esteve Serrano (1982) destaca su propuesta fonetista, e Infantes y Martínez lo incluyen en su estudio/facsímil (2003) sobre cartillas de lectura y silabarios.

La faceta del profesor asturiano en tanto que ortólogo apenas ha sido atendida, salvo los recientes trabajos de Satorre y Viejo (2013), o Quijada (2014 y en prensa). Ello puede explicarse, en parte, porque tradicionalmente ha sido considerado un autor menor en lo que a las cuestiones fónicas se refiere, siempre bajo la sombra de la monumental obra de Sicilia. En los apartados que siguen pretendemos destacar las aportaciones originales de su obra ortológica y señalar sus deudas intelectuales con la tradición francesa. González de Valdés puede considerarse como el introductor de la teoría ilustrada sobre formación mecánica de la voz y otros datos sobre fonética general en la lingüística española, de ahí su relevancia para la historia de las ideas fónicas y la importancia de un análisis contrastivo.

\section{LA ORTOPEIA EN LA TRADICIÓN LINGÜÍSTICA ESPAÑOLA}

En toda su producción procede mediante un sistema de desglose por niveles de los contenidos: en las gramáticas separa tipográficamente las notas más avanzadas y complejas, y en su obra fónica prepara silabarios prácticos para los estudiantes y obras más reflexivas para los profesores. La Ortopeia es un texto dirigido al maestro, en el que más que información descriptiva o normativa sobre pronunciación, el interés de sus aportaciones gira en torno a la teoría de la articulación y fonación humanas (fonética general), al desajuste grafía/sonido y a las indicaciones pedagógicas sobre la enseñanza de la lectoescritura.

\subsection{Descripciones articulatorias de los Elementos SEgmentales}

Para calibrar el alcance doctrinal de sus descripciones articulatorias, hemos de contrastar la información que proporciona con la que muestran otros ortólogos, ortógrafos, gramáticos o logopedas de la época. El lenguaje oral, y en particular su materia fónica, ha sido atendido desde los orígenes gramaticográficos. En nuestra tradición lingüística, a partir del siglo XVI suelen ser las cuestiones segmentales y la acentuación las que reciben 
mayor atención, es decir, aquellas vinculadas más estrechamente a la ortografía ${ }^{3}$.

No es nuestro propósito entrar en detalle sobre la aportación de los autores (remitimos para ello a las obras clásicas de Alonso 1967-1969 o Esteve 1982), puesto que es muy desigual y sería extremadamente difícil ofrecer una visión de conjunto. La consulta de tales estudios, junto a los de Martínez Alcalde (cfr. nota anterior) y el de Satorre y Viejo sobre ortologías (2013), se hace imprescindible para determinar los principales hitos descriptivos y los autores paradigmáticos en materia fónica.

Por este motivo, en este apartado nos hemos fijado únicamente en la descripción de los sonidos aislados (nivel segmental). A diferencia de las gramáticas, ortografías y algunas ortologías, que describen los sonidos siguiendo el orden alfabético de las letras con que se representan (a veces no se incluyen todos, sino tan solo aquellos más problemáticos en relación con su escritura), la presentación de González de Valdés es exclusivamente fonética:

a) Sonidos orales simples (= vocales, ordenadas según el "estado del canal ó cuerda de la voz")

b) Sonidos instrumentales simples (= consonantes, ordenadas según "el estado del canal" y los "movimientos de los órganos")

- Labiales $(/ \mathrm{m} /, / \mathrm{b} /, / \mathrm{p} /, / \mathrm{f} /)$

- Articulados con la lengua y los dientes $(/ \mathrm{d} /, / \mathrm{t} /, / \theta /)$

- Articulados con la lengua y el paladar (/l/,/n/, / / /, /r/, ///,/s/, / $\lambda /)$

- Guturales (/g/, /k/, /x/)

c) Sonidos compuestos

- "phthongo" (una vocal)

- "diphthongo" (dos vocales)

- "triphthongo" (tres vocales)

Otros ortólogos, como Sicilia (1827-1828 [1832]), también proponen clasificaciones de los sonidos consonánticos atendiendo a su lugar de articulación. Este menciona, además, otras posibles clasificaciones a partir de criterios diferentes (acción del velo del paladar, modo de articulación:

\footnotetext{
Las cuestiones métricas y el valor de las sílabas, propias de la prosodia clásica, son asuntos que entran y salen de la gramática española de manera intermitente a lo largo de su historia. A finales del siglo XVIII y, sobre todo, durante el XIX, la prosodia se consolida tras la aparición de las obras de Sicilia y de Bello, y solo en ese momento la Academia se decide a incluirla en su obra gramatical (1870). A este respecto, es recomendable consultar los trabajos de Martínez Alcalde sobre las competencias y las intersecciones disciplinares entre prosodia, ortología, ortografía y gramática en el ámbito hispánico (entre otros, cfr. 2010, 2013 y 2014).
} 
orales/nasales, silbantes, suflantes ${ }^{4}$ ), datos que también aporta González de Valdés aunque sin establecer una taxonomía cerrada.

En cuanto a precisión y distinción de rasgos (lugar, modo y tensión articulatorias, oralidad/nasalidad), la información de la Ortopeia se sitúa en el promedio de la época. A pesar de que lógicamente las observaciones no son uniformes y de que hay gramáticos (ortógrafos, ortólogos) que proporcionan datos muy técnicos, si se toma a Martínez Gómez Gayoso y a Sicilia como términos de la comparación ${ }^{5}$ se comprueba que las apreciaciones de Valdés se ajustan a ese continuum:

\begin{tabular}{|c|c|c|}
\hline $\begin{array}{c}\text { B. Martínez } \\
\text { Gómez Gayoso } \\
1743 \text { [1769] }\end{array}$ & $\begin{array}{l}\text { J. A. GonZÁLEZ DE } \\
\text { VALDÉS } 1785\end{array}$ & $\begin{array}{c}\text { M. J. SiCILIA } \\
1827-1828[1832]\end{array}$ \\
\hline $\begin{array}{l}\text { La } \mathrm{P} \text {, letra muda, se forma } \\
\text { cerrando los labios por la } \\
\text { parte de afuera algo mas } \\
\text { recio que para pronunciar } \\
\text { la } \mathrm{B} \text {, è hiriendo con el } \\
\text { aliento ácia fuera; y su } \\
\text { sonido es } P e \text {. Viene del } \\
\text { Griego } P i \text {. Despues de las } \\
\text { muchas significaciones } \\
\text { que dieron los antiguos } \\
\text { á esta letra, valía por el } \\
\text { número de quatrocientos } \\
\text { (16-17). }\end{array}$ & $\begin{array}{l}\text { [sonido labial oral] Si } \\
\text { cerrada antes la boca, } \\
\text { menos hinchados los } \\
\text { carrillos, y mas apretados } \\
\text { los labios, se despide una } \\
\text { corta respiracion con algo } \\
\text { mas de violencia [que para } \\
\text { b], se señala la articulacion } \\
\text { del sonido en griego con } \\
\Pi \pi \text {, y en latin con } P \text { p, } \\
\text { letras llamadas tenues por } \\
\text { la brevedad y sutileza } \\
\text { de la respiracion que } \\
\text { significan, cuyo sonido } \\
\text { medio entre el antecedente } \\
{[b] \text { y el siguiente [ } \varphi \text { ] es }} \\
\text { muy parecido al pio de los } \\
\text { pollitos (122-123). }\end{array}$ & $\begin{array}{l}\text { M. ¿A qué género de } \\
\text { articulaciones pertenece } \\
\text { la de p? } \\
\text { D. Al de las labiales. } \\
\text { M. ¿Cómo se practica? } \\
\text { D. J u n t a n d o lo s } \\
\text { labios naturalmente, } \\
\text { comprimiéndolos un poco } \\
\text { para afuera, y soltándolos } \\
\text { con un poco más de fuerza } \\
\text { que para la b al tiempo } \\
\text { de emitir el sonido vocal } \\
\text { (143). }\end{array}$ \\
\hline
\end{tabular}

Tabla 2. Descripción del sonido /p/ en Martínez Gómez

Gayoso, González de Valdés y Sicilia

4 No obstante, añade esta información solo como curiosidad para quienes lean a otros autores, puesto que cree que no tiene una particular utilidad (1832: 33).

5 Martínez Gómez Gayoso es el primero en introducir un apartado de "ortología” en un tratado gramatical (1743), junto a la ortografía y separado de la prosodia, siguiendo de cerca los postulados ortográficos académicos (1741). Junto a él, hemos seleccionado a Sicilia por ser considerado el primer ortólogo español (su obra Lecciones elementales de ortología y prosodia tendrá un enorme éxito en España e Hispanoamérica). 
Tres pueden considerarse las peculiaridades descriptivas de la Ortopeia, que la distancian del quehacer habitual: (a) incluir apreciaciones dialectales, como la [t] alveolar y [S] prepalatal fricativa sorda ${ }^{6}$ asturianas, o la [3] prepalatal fricativa sonora vasca, (b) contrastar los sonidos con realizaciones de las lenguas clásicas (sistemáticamente) o vernáculas (incorpora abundantes comentarios sobre el francés y algunos sobre el alemán, italiano, portugués o inglés), y (c) mostrar y condenar las desviaciones ortológicas de los españoles con respecto a las pronunciaciones griega y latina (no olvidemos que el fin último de González de Valdés es enseñar latín). Como botón de muestra de las tres características se propone el ejemplo de la letra jota:

$J j$ esta letra se introduxo sin necesidad y con mucho perjuicio en la lengua latina en lugar de la letra vocal $I i$, que con el nombre de Iota se conserva en la lengua griega origen de la latina. Porque es superflua, y causa de que se yerre la pronunciacion de muchas palabras latinas y griegas adoptadas en latin, articulándolas con sonidos mal divididos: v. gr. a jo en lugar de ai o, ó con un sonido menos, v. gr. Ja zyx Julus, en lugar de Ia zyx Iulus. Estos yerros pasaron tambien á la lengua Española en muchas palabras tomadas de la griega o latina, v. gr. Jonia, Jason, Jota, en lugar de $I o$ nia, I a son, I o ta. Y así en fuerza del uso antepuesta la expresada figura á qualquiera de nuestras vocales, señala aquella respiracion tosca floxa, que estrechando muy poco las fauces despedimos al cielo de la boca abierta con la lengua algo encorvada, lo qual no pueden executar los Franceses. En el dialecto Asturiano, en el qual se encuentra mucho del castellano antiguo, la letra $J j$ no significa la articulacion morisca referida, sino una respiracion que se despide suavemente estrechando un poquito las fauces con la lengua casi entre los dientes, entreabiertos estos y los labios, la misma que los Franceses significan con $\mathrm{CH}$ ch (González de Valdés 1785: 151-153).

Aunque si comparamos la calidad descriptiva de González de Valdés con aquella procedente de la tradición sordomudística española (a la que apela como autoridad en varias ocasiones, pero no parece emplear como fuente directa), se podría calificar de algo más rudimentaria e imprecisa. Por

\footnotetext{
6 Así es descrita: "Los Asturianos nunca dominados por los Moros en lugar del sonido Morisco gutural que los demás Españoles significan con la letra X, representan en su dialecto con la misma letra aquel sonido dulce y agradable, que resulta soplando moderadamente con la punta de la lengua detras de los dientes con los labios entrabiertos, sin tocar con ella en ninguna parte. Este sonido es semejante al que percibimos de los comestibles que están friyéndose á fuego lento, y al del movimiento de las hojas de los árboles causado por algun viento suave" (1785: 156-157).
} 
ejemplo, en la descripción de /s/, todos los autores (salvo Hervás y Panduro) aluden al silbido de la serpiente y al lugar/modo de articulación. Quienes se dirigen específicamente a los sordomudos tratan de ser más minuciosos e indican la parte exacta de la lengua -aquí hay diversidad de opiniones, puede ser apical o predorsal-, la parte exacta de la boca, la curvatura de la lengua y la tensión de la salida de aire:

\begin{tabular}{|c|c|c|c|}
\hline $\begin{array}{c}\text { SEBASTIÁN } \\
1619 \\
\end{array}$ & $\begin{array}{c}\text { BONET } \\
1620 \\
\end{array}$ & $\begin{array}{l}\text { J. A. GonZÁLEZ } \\
\text { DE VALdÉS } 1785\end{array}$ & $\begin{array}{c}\text { HERVÁS Y PANDURO } \\
1795 \\
\end{array}$ \\
\hline $\begin{array}{l}\text { Para sonar, y hazer } \\
\text {.s. la boca ninguna } \\
\text { necessidad tiene } \\
\text { de vocal. Como } \\
\text { diximos de la .f. } \\
\text { dezimos de la .s. } \\
\text { que el espiritu solo, } \\
\text { que la boca despide, } \\
\text { por la puerta, que la } \\
\text { lengua apretada, } \\
\text { por el lomo, al } \\
\text { paladar alto, y } \\
\text { apartada la punta, } \\
\text { de los dientes, le } \\
\text { dexa muy estrecha, } \\
\text { haziendo, hiera los } \\
\text { dientes altos de lo } \\
\text { delgado, y como } \\
\text { en lo afilado de } \\
\text { vn cuchillo, haze } \\
\text { alli, en el corte, de } \\
\text { los dientes, aquel } \\
\text { sonido, que es como } \\
\text { el sylvo, o cisclo de } \\
\text { la serpiente: con } \\
\text { esto solo, queda } \\
\text { formado perfecto } \\
\text { son de.s. (26-26vo). }\end{array}$ & $\begin{array}{l}\text { Esta letra S. tiene } \\
\text { por nombre, el } \\
\text { sonido de vn } \\
\text { siluo baxo muy } \\
\text { suave, que se } \\
\text { forma con poca } \\
\text { r e s p i a c i o n } \\
\text { tocando la punta } \\
\text { de la lengua en } \\
\text { el principio de la } \\
\text { encia superior, } \\
\text { que participen } \\
\text { algo los dientes. } \\
\text { A este caracter } \\
\text { no le guardaron } \\
\text { forma apropiada } \\
\text { a la accion de } \\
\text { la boca, sino al } \\
\text { animal que con } \\
\text { siluos quiere } \\
\text { ex pres ar su } \\
\text { instinto, que es } \\
\text { la culebra, y assi } \\
\text { se le dio a esta } \\
\text { letra la figura } \\
\text { della (100). }\end{array}$ & $\begin{array}{l}\text { La articulacion } \\
\text { de la voz que se } \\
\text { executa con la } \\
\text { punta de la lengua } \\
\text { casi unida al borde } \\
\text { del paladar delante } \\
\text { de los dientes } \\
\text { s uperiores un } \\
\text { poquito desunidos } \\
\text { de los inferiores; } \\
\text { y forma un silvo } \\
\text { suave sin fruncir } \\
\text { los labios ni } \\
\text { avanzarlos; se } \\
\text { escribe en Griego } \\
\text { con } \Sigma \sigma \text { figura del } \\
\text { arco de los Escitas, } \\
\text { y en Latin con S } \\
\text { figura de culebra } \\
\text { enroscada. Este } \\
\text { sonido se parece } \\
\text { al de los pollitos. } \\
\text { En lengua francese } \\
\text { es muy dulce y } \\
\text { sostenido, quando } \\
\text { se articula entre } \\
\text { dos orales puros } \\
\text { casi semejante al } \\
\text { representado en la } \\
\text { letra } Z \text { (138-139). }\end{array}$ & $\begin{array}{l}\text { Para pronunciar sa, } \\
\text { la punta de la lengua } \\
\text { toca en la extremidad } \\
\text { del paladar hácia los } \\
\text { dientes superiores } \\
\text { delanteros: esto } \\
\text { es, toca un poco } \\
\text { mas alto, y menos } \\
\text { fuertemente que } \\
\text { para pronunciar za. } \\
\text { Asi mismo la lengua } \\
\text { para pronunciar sa } \\
\text { se dobla en medio, y } \\
\text { no toca la extremidad } \\
\text { del paladar con el } \\
\text { ápice de su punta, } \\
\text { sino con una parte } \\
\text { un poco más interior } \\
\text { que el dicho ápice. } \\
\text { En esta situacion de } \\
\text { la lengua se respira, } \\
\text { encanalando el aliento } \\
\text { para que salga entrelos } \\
\text { dientes, y el ápice de } \\
\text { la lengua al separarse } \\
\text { ésta del paladar. El } \\
\text { aliento, al pronunciar } \\
\text { sa, es muy sensible, y } \\
\text { su direccion va muy } \\
\text { hácia abaxo, como se }\end{array}$ \\
\hline
\end{tabular}




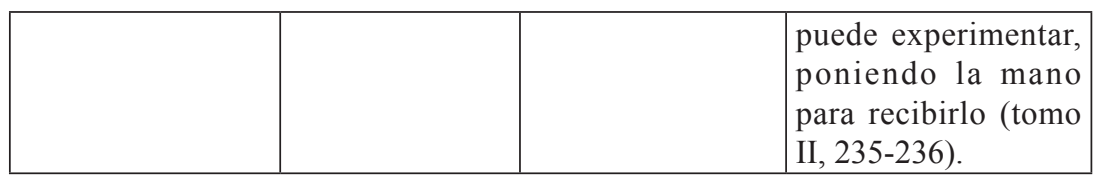

Tabla 3. Descripción del sonido/s/ en Sebastián, Bonet, González de Valdés y Hervás y Panduro

Es evidente que tanto Bonet como Hervás y Panduro se proponen enseñar a los sordomudos y que sus instrucciones han de ser a la fuerza más precisas. Este último no parece conocer la Ortopeia cuando prepara su Escuela de Sordomudos (1795); en cambio, sí conoce y alaba los Silabarios y la gramática, tal y como se desprende de la carta incluida en la Gramática completa grecolatina y castellana de González de Valdés ${ }^{7}$.

Las comparaciones con sonidos de animales o de elementos de la naturaleza serán de gran ayuda a los maestros cuando se dirijan a los niños, y como tales recursos didácticos hay que entender estos datos impresionistas tan característicos de la Ortopeia:

[sobre /r/ ] El sonido tosco que resulta de la respiracion tan fuerte, que fixa la punta de la lengua en la concavidad del paladar, la haga tremolar dentro de la boca entreabierta con un movimiento semejante al de la luz artificial; es un sonido parecido al ruido de las hojas de los árboles, que impelidas por el viento vuelven á quedarse en su lugar; y al del molino, juego pueril compuesto de dos nueces y un exe, ó de otra qualquiera materia: y le representa siempre la letra griega $P \rho$, y la latina $R H, r h$, letras aspiradas todas, $\mathrm{y}$ representativas del expresado sonido tosco, imposible de articular por los Chinos (González de Valdés 1785: 133-135).

\footnotetext{
7 "Mi señor y dueño, el silabario y la nueva gramática latina y castellana, que el señor Don Juan Antonio González de Valdés ha publicado en Madrid, me han presentado leccion de placer. Con este en el silabario he leido propuesta anticipadamente, practicada y publicada en el año de 1779 la idea que yo sobre el deletrear insinué en mi historia del hombre empezada á publicar en 1789 [...] y en la escuela española de Sordomudos en 1795 [...] He visto que antes de estos años estaba ya crecida tal idea, que yo miraba mas por su racionalidad y utilidad, que por creerla mia. El señor González de Valdes, humano con la infancia y con las ciencias, ha propuesto en su silabario el modo de facilitar la entrada a éstas" ("Calificaciones a la gramática”, 1798).
} 


\subsection{INDEPENDENCIA DEL COMPONENTE ORAL DEL LENGUAJE}

Como en otros textos de González de Valdés, en la Ortopeia se vuelve a insistir en la importancia capital de separar el plano escrito del oral. Así, algo menos de un tercio de la obra va destinado precisamente a señalar la inadecuación ortografía-pronunciación ${ }^{8}$. Es un tema recurrente y habitual en la época, que se venía formulando desde siglos atrás. Pero antes de 1785, tal vez pocos autores lo expresen con la escrupulosidad, rigor y claridad de González de Valdés: más que señalar el desajuste ortográfico le interesa desterrar de una vez por todas la tradicional y anquilosada equivalencia "letra = sonido". Y su empeño cala en toda la obra: desde la formulación de la idea misma, pasando por una detallada exégesis de un texto nebrisense, la descripción de los sonidos a través un orden fonético y no alfabético, hasta la precaución, de principio a fin de la obra, para no expresarse equívocamente:

(a) Formulación de la idea:

El uso de las sílabas y las letras ha sido y será siempre tan provechoso, que embelesados los hombres con tan maravillosa invencion, confundieron no solo los nombres de los sonidos y de la voz con los nombres de las letras ó pinturas de los sonidos, llamando tambien á los sonidos letras, y á las letras sonidos vocales, sonantes, y consonantes; sino que por letras se entienden ya las artes liberales, y las ciencias, particularmente el arte y ciencia de hablar bien [...] la letra ni es voz, ni parte de la voz, ni lo que se pronuncia es la figura, sino la voz ó el sonido representado en ella: letra es una figura visible ó palpable, y la voz es invisible y no palpable. Si las letras consonantes se escriben, esto es, si se hacen figuras para representar lo invisible, aplicando, por decirlo así, un determinado color á cada sonido; deben significar algo después de escritas ó hechas, pues de lo contrario son inútiles y superfluas. Este algo es sin duda una articulacion de la voz... (González de Valdés1785: 67, 70-71).

(b) Comentario del texto nebrisense: rebate la opinión de Nebrija de que "consonante es letra que no se puede pronunciar sin ayuda de alguna vocal" o "letra es la menor parte de la voz que se puede escribir"; pero sí está de acuerdo cuando el sevillano proclama en su Gramática que "no es otra cosa la letra que una figura, por la qual se representa la voz".

8 Cfr. en especial el fragmento pp. 159-165. 
(c) Describe los sonidos por orden articulatorio desde fuera hacia adentro. En el capítulo II explica la pronunciación de los sonidos consonánticos siguiendo su lugar de articulación: "labiales", "lengua + dientes", "lengua + paladar" y "guturales".

(d) Cuida la formulación. Desde el propio título de la obra: "sonidos simples y compuestos demostrados con exemplos visibles en las letras y sílabas de palabras escritas" o en la descripción de los sonidos: "el sonido $x$ se representa con la figura $y$ " ("se estampa", "se escribe", etc.).

Hay, además, una consecuencia teórica de mayor calado: critica la habitual división (que continuará mucho más adelante) de las letras consonantes en mudas, líquidas y semiconsonantes, por tres motivos: (i) las letras son "inánimes", por lo que adjudicarles propiedades propias de seres vivos no tiene lugar, (ii) esta clasificación no puede ser universal, ya que depende del nombre que cada lengua particular le otorga y (iii) en ningún caso alude al sonido que representa cada letra cuando se combina con alguna vocal. No hemos encontrado ningún otro autor de nuestra tradición (ni de la francesa) que se aparte en estos términos de la conocida clasificación de origen griego:

La subdivision de las consonantes en semivocales, líquidas, y mudas, siendo todas las letras ni mudas ni muertas, sino realmente inánimes; y la definicion que se aplica á estas tres especies, recaen sobre el accidente del nombre particular, que da cada nacion á cada una, sin sujetarse á la articulacion o sonido simple é imperfecto que representan combinadas despues de las vocales en la oracion escrita (González de Valdés 1785: 79).

\subsection{Mecanismos de FonÉtica General} (ARTICULATORIOS Y ACÚSTICO-PERCEPTIVOS)

Otro tercio de la obra va destinado a explicar los principios de fonación y articulación humanas. Este parece ser, salvo error por nuestra parte, uno de los primeros textos de carácter lingüístico de la tradición hispánica en insertar nociones de fonética general. Los avances de la época en materias como fisiología animal, medicina, mecánica o física acústica propician que los estudios sobre la voz humana se refinen a lo largo del siglo ilustrado, especialmente en Alemania, Inglaterra o Francia. De este país proceden las fuentes de González de Valdés. Los principios ilustrados generales impregnan 
la Ortopeia desde el propio título de la obra: Ortopeia universal ó arte de pronunciar segun los principios físicos elementales ${ }^{9}$.

En Francia, a partir de la Gramática general y razonada de Port Royal (1660) comienza a sucederse toda una serie de obras -los comentarios a Port Royal de Duclos; las gramáticas generales de Buffier, Du Marsais, Beauzée, artículos enciclopédicos; obras ortográficas y ortológicas como las de Harduin o Brosses; sobre enseñanza de la lectoescritura: Pluche o Launay; los ensayos médicos de Dodart o Ferrein- a través de los cuales el estudio de los sonidos del lenguaje conoce un impulso definitivo en el siglo $\mathrm{XVIII}^{10}$. Es en este periodo cuando se consolida la consideración del lenguaje como objeto físico y mesurable, que corre paralelo (en estrecha vinculación, eso sí) a su vertiente inmaterial y abstracta, reflejo del pensamiento. Los trabajos de los filósofos cartesianos (Cordemoy, Discours physique de la parole 1668; Lamy, La Réthorique ou l'art de parler 1675) coadyuvan a una mayor atención por los aspectos físicos y mecánicos de la palabra a partir del siglo siguiente en las obras lingüísticas (Bouton 1984: 66).

En nuestro país, tras la iniciación de González de Valdés, habrá que esperar al siglo XIX para encontrar descripciones generales sobre fonación y articulación: en obras como la de Sicilia (1827-1828 [1832]) o Noboa (1839) se plasman con mayor precisión los avances en fonética general. Los autores que adoptan un punto de vista lingüístico en sus obras y deciden insertar algunas nociones básicas sobre la formación fisiológica y acústica del habla en ciertas ocasiones se sienten obligados a disculparse al lector (como De Brosses ${ }^{11}$ ). Otros, como Torío de la Riva, incluso prescinden de estos datos alegando que no son necesarios para los maestros, sino solo para

9 Sin embargo, la alusión a esta disciplina retórica (orthoepeia), habitual entre los tratados de pronunciación de las lenguas clásicas en el Renacimiento y los siglos XVI y XVII, no es tan frecuente en el ambiente francófono durante el periodo ilustrado. Sí lo es en Inglaterra, cuando el Elocutionary Movement revitaliza el uso de dicho término: encontramos, entre otros muchos ejemplos, los Elements of Orthoepy de Robert Nares, publicados en 1784 (cfr. Abercrombie 1948 y Beal 1999).

10 Cfr. para una revisión de las ideas fónicas en Francia en el siglo XVIII los trabajos de Auroux y Calvet 1973, Auroux 1979, Swiggers 1984a y b, Fournier 2007a y b, Rey 2007 y 2011, entre otros.

11 "Dans le cours de cet ouvrage, je serais souvent obligé de procéder à l'anatomie des mots. Le genre de mon suget exige cette espèce de travail, réellement minutieux aux yeux de tout le monde, comme aux miens, et que beaucoup de personnes, à qui je ne serais pas en peine de repondre bientôt, regarderont comme inutile, même dans son objet. Mais je ne m'arrête aux mots que pour arriver aux choses" (1765 [1801]: 21-22). 
los médicos ${ }^{12}$. No es el caso de nuestro autor; en su opinión, esta información es fundamental en la enseñanza de la pronunciación.

Así pues, estas dos particularidades de la Ortopeia que, en mayor o menor medida la diferencian del grueso de obras de la tradición española (a saber: defensa de la no correspondencia letra-sonido y reivindicación del plano oral, junto con las nociones fisioacústicas de la voz) son los pilares necesarios para sustentar el avance de la disciplina, tal y como señala Auroux:

Sans être radicalement nouvelle, puisqu'elle a son origine aussi bien au XVIII ${ }^{\mathrm{e}}$ siècle qu'à la Renaissance, l'étude des sons du langage revêt au $\mathrm{XVIII}^{\mathrm{e}}$ siècle une ampleur particulière [...] Les progrès proviennent de deux sources distinctes. L'un des sources est l'abandon progressif de la correspondance son-lettre [...] les auteurs reconnaissent la fantaisie de l'orthographe, et l'oralité paraît l'un des points déterminants de l'existence de la langue [...] Chaque progrès de la phonétique est comme un désaveu de la liaison son/lettre instaurée par l'orthographe et s'accompagne d'une augmentation des sons distingués [...] La seconde source est la constitution décisive de la phonétique acoustique et organique (Auroux1979: 249-250).

\section{LAS FUENTES FRANCESAS DE LA ORTOPEIA}

Las autoridades francesas explícitamente mencionadas en la obra son: el abad L'Épée (p. 86), el Curso de estudios de Condillac (p. 86), el Tratado de la formación mecánica de las lenguas y principios físicos de la etimología de De Brosses (p. 165), Ferrein (p. 215), las Observaciones a la gramática de Port Royal de Duclos (p. 219), el Diccionario enciclopédico (p. 226) y la Lógica y los principios de gramática de Du Marsais (p. 248). Cita extractos literales (con indicación de la edición empleada, número de capítulo y página) de Condillac, De Brosses, Duclos y Du Marsais. Hay también una alusión vaga a los "franceses" que denominan a un determinado sonido "vocal muda o sorda".

12 "No me detendré á esplicar el modo con que sale el ayre de los pulmones, y pasando por la traquiarteria, empieza á modificarse para la voz en la laringe, la glotis y la epiglotis, porque esta y otras semejantes observaciones físicas, además de la obscuridad que traen consigo, son más bien propias de un anatómico que de un maestro de leer" (1804: 17). 
Cuando iniciamos el rastreo de las fuentes de González de Valdés nos fijamos desde un primer momento en sus datos fisioacústicos, que necesariamente habrían de contar con un aval científico externo. Así pues, examinamos la información fónica de las obras enciclopédicas (la Enciclopedia de Diderot y D'Alambert, y la Enciclopedia metódica preparada por Beauzée) y, aunque es cierto que comparten numerosas concepciones prototípicas de la época (voz articulada vs. voz inarticulada, sonido oral puro vs. instrumental, comparación del instrumento de la voz con un instrumento musical, diferencia entre las nociones de sonido y voz, mecanismo de resonancia, actividad glotal, etc.), su alto grado de tecnicidad y su terminología nos hicieron suponer que tal vez no fuesen las fuentes directas de nuestro autor.

Efectivamente, en la página 165 declara González de Valdés: "Parte de esta obra se ha traducido del tratado de la formacion mecánica de las lenguas y principios físicos de la etimología, compuesto por el Presidente de las Brosses de la Academia de las Bellas Letras de Paris, en donde se ha impreso año de 1765". Charles De Brosses, jurista y erudito francés, compone esta obra lingüística de importante calado teórico que es bien acogida entre los intelectuales de la época (la Enciclopedia recoge alguna de sus propuestas, autores como Buffier o Condillac la alaban -no Voltaire, con quien está enemistado- y Jovellanos adquiere un ejemplar para su biblioteca -tal vez sea quien recomiende su lectura a González de Valdés-) y su recepción en el extranjero es rápida: en 1777 ya se traduce en Alemania. Este tratado está considerado uno de los primeros modelos generales que tratan de explicar la constitución y el desarrollo de las lenguas; además, otra originalidad constituye su proyecto de alfabeto fonético universal. El principal objetivo que persigue es "d'observer les opérations corporelles de l'organe vocal [mecánica de lenguas]. Celui d'observer les opérations de l'esprit humain dans l'usage de la parole et dans la fabrique des mots n'est que le second" (Auroux 1979 y 2000).

\subsection{LA RECEPCIÓN DEL TRAITÉ DE LA FORMATION MÉCHANIQUE DES LANGUES ET DES PRINCIPES PHYSIQUES DE L'ÉTYMOLOGIE de De Brosses (1765) en la ORTOPEIA}

Un análisis contrastivo entre el tratado de De Brosses y la Ortopeia revela una importante deuda del autor español. Este reconoce la traducción de diversos pasajes, pero dicho reconocimiento se realiza en un lugar donde precisamente no es utilizado (descripción de los sonidos consonantes) y, además, viene acompañado de una remisión a la segunda parte del tratado, 
apenas explotada por González de Valdés. De manera más o menos literal, el primer volumen del francés está presente en bastantes pasajes de la Ortopeia. Hemos clasificado su influencia dependiendo de si atañe a: (i) cuestiones de fonética general (la mayoría), (ii) cuestiones ortográficas o (iii) pronunciación de lenguas particulares.

\subsubsection{Cuestiones de fonética general}

- Las definiciones que propone González de Valdés de "sonido", "sonido oral puro" (representado por las vocales) y "sonido instrumental" (representado por las consonantes) son extraídas de De Brosses $^{13}$. En un sonido (unidad considerada por ambos "indivisible", "instantánea" y de "cortísima duración"), la "materia o sustancia" es la vocal y el "modo o forma", la consonante. González de Valdés, asimismo, trae a la Ortopeia la denominación francesa -en su opinión "contradictoria" y errónea- de "vocal muda o sorda" (cfr. apartado 1.2.).

- El instrumento de la voz, según De Brosses y, con él fielmente la Ortopeia $^{14}$, es el canal que va desde la zona inferior de la garganta hasta los labios. Los estados de este canal son infinitos (múltiples tamaños y volúmenes), de ahí que los autores concluyan que existen infinitas variedades de vocales. Cada lengua particular divide el "diapasón de la escala de su voz" de forma específica, por lo que una misma palabra pronunciada por hablantes de naciones diferentes no sonará igual. En lo que parecen tener opiniones distintas es en el número de "divisiones más comunes" o "posiciones del sonido simple puro"; mientras que De Brosses establece siete, González de Valdés apunta seis: 


\begin{tabular}{|l|l|}
\hline DE BRosses & GonZÁLEZ DE VALDÉS \\
\hline On remarque communément sept & Se observan comúnmente seis divisiones \\
divisions plus marquées du son simple, & ó posiciones del sonido simple como las \\
ou sept états du tuyau qu'on appelle & mas conocidas, á las quales llaman \\
voyelles, $a, \eta, e, i, o, 8[=o u], u$. Mais & vocales, y se figuran así a, e, $i, u, u$, \\
il est clair qu'une ligne ayant autant de & $v$. Pero es evidente, que teniendo una \\
parties qu'il y a de points indivisibles, & línea tantas longitudes como tiene de \\
qui la composent dans tout sa longueur, & puntos indivisibles en toda su longitud, \\
il y a autant de voyelles qu'il peut y avoir & resultan de esta línea vocal ó de la voz \\
de divisions intermédiaires entre les sept & otros tantos sonidos, como divisiones \\
ci-dessus, d'où il suit qu'il y en a une & intermedias puede haber entre las seis \\
infinité (1765 [1801]: 98). & comunes (1785: 7-8). \\
\hline
\end{tabular}

Tabla 4. Número de sonidos simples puros en De Brosses y González de Valdés

Esta propuesta general sobre las divisiones del canal de la voz contrasta con la concepción de Sicilia (1832: 16), centrada en la lengua española, el cual distingue dos tipos de vocales -"puras" y "mixtas"- según sean las cinco españolas ("puras") o extranjeras ("mezcladas", que participan de al menos dos españolas) (Quijada, en prensa).

- Para explicar de forma sencilla la composición del sonido en "voz + articulación", De Brosses abstrae su teoría y anuncia una fórmula general válida para todas las lenguas: solo existe un único sonido simple puro (generado en la laringe) y un número variable de sonidos articulados dependiendo del número de órganos que emplee cada lengua para pronunciar. González de Valdés calca dicha teoría y, al traducir, se lleva uno de los pocos descuidos de la Ortopeia, ya que equipara "sonido" con "letra" ("estos son los movimientos impresos en el sonido, á los quales llaman letras consonantes") ${ }^{15}$.

- Es un lugar común entre los textos europeos de la época comparar la fonación y articulación humanas con el mecanismo de los instrumentos musicales. El profesor asturiano, en un primer momento, las compara con la flauta, siguiendo a De Brosses, a pesar de que ambos opinen que se trata de una comparación "inexacta"16.

15 De Brosses (1765[1801]: 95-96 y 99-100) y González de Valdés (1785: 8-10).

16 González de Valdés (1785: 11-13) y De Brosses (1756[1801]: 100). Sicilia hará lo propio tomando a Harduin como referencia (Dissertation sur les voyelles et les consonnes, 1760). 
- Pero a continuación les parece más apropiado relacionarlas con un instrumento de cuerda: la cuerda (o tracto vocal) se alarga o acorta y así se obtienen las diferentes vocales. Mantener tal vinculación con los instrumentos de cuerda conlleva distinguir y definir los sonidos vocálicos únicamente según criterios tonales (acústicos o perceptivos) y dejar de lado los articulatorios ${ }^{17}$ (aunque estos sí serán empleados con mayor o menor pericia en la descripción posterior de cada vocal $)^{18}$. La esquematización de su gradación tonal por medio de una línea queda plasmada así:

17 Auroux (1979: 252-253) destaca la inconsistencia de ciertos autores (Brosses o Harduin) al identificar la vocal con el tono: "En identifiant la voyelle avec le son, la bouche avec une flûte ou une corde, ils ne peuvent distinguer les voyelles que par des hauteurs de ton. Il en résulte (puisque l'échelle des tons est continue) que les différents voyelles peuvent être classées sur une échelle continue, et que par conséquent on ne peut les distinguer exactement". De donde se deduce que en estos autores (a diferencia de Beauzée y las teorías enciclopédicas) la idea de "articulación vocálica" no está aún afianzada.

18 Contrástense las descripciones de la vocal /e/ en González de Valdés y Hervás y Panduro. Mientras que la abertura articulatoria es claramente reconocida por ambos, tan solo el conquense explica el lugar de articulación de dicho sonido:

\begin{tabular}{|c|c|}
\hline GonZÁlez de VALdÉs & Hervás y Panduro \\
\hline $\begin{array}{l}\text { La que se despide con la boca entreabierta, y } \\
\text { los labios algo retirados ácia dentro, se señala } \\
\text { con una de estas tres } E, \varepsilon, e(1785: 104) \text {. }\end{array}$ & $\begin{array}{l}\text { La vocal } e \text { se pronuncia teniendo la boca } \\
\text { menos abierta que estaba para pronunciar } \\
\text { la } a \text { : el labio inferior se retira un poco } \\
\text { hácia dentro, se baxa insensiblemente, y } \\
\text { consiguientemente se ensancha algo hácia } \\
\text { sus lados. La lengua está un poco mas } \\
\text { estendida que para pronunciar la } a \text {, y su punta } \\
\text { se encorva un poco hácia la raiz de los dientes } \\
\text { baxos delanteros (1795: } 219-220 \text {, tomo II). }\end{array}$ \\
\hline
\end{tabular}




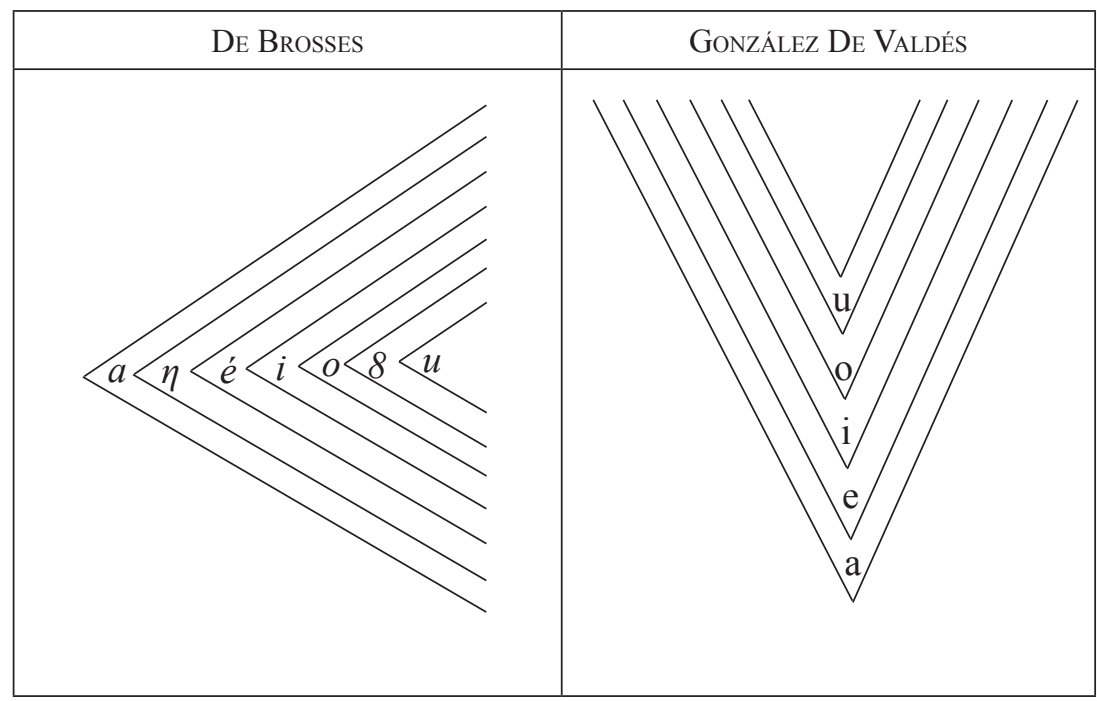

Tabla 5. Divisiones de la cuerda de la voz en De Brosses y González de Valdés

- De Brosses clasifica a las vocales a su vez en "sourde" (representada por e), "franche" (é) y "sonora" ("nasal y cantada": en); esta taxonomía de criterio prioritariamente perceptivo y adaptada a las vocales francesas es traducida por González de Valdés sin ningún tipo de explicación ("sorda", "abierta" y "sonora": para las que no da ningún ejemplo) $)^{19}$.

- En la clasificación de los sonidos consonánticos los criterios aún no están delimitados en esta época. Por un lado, se evita dar rasgos acústicos (son exclusivos de las vocales), por lo que no encontramos una distinción entre consonantes sordas y sonoras; por otro, no parece establecerse como criterio estable el modo de articulación. La clasificación propuesta por De Brosses y calcada en la Ortopeia, alude a la perceptibilidad y "fuerza" (o tensión articulatoria) de las articulaciones ${ }^{20}$. Los términos "douce", "moyenne" y "rude" se traducen por "flojo"/ "dulce", "medio" y "fuerte"/ "tosco". Sin embargo, más adelante, en el momento de describir cada sonido (capítulo II) o en su Silabario trilingüe, al no seguir literalmente 
las pautas de De Brosses, González de Valdés se permite ciertas variaciones con respecto a lo afirmado en la introducción e, incluso, reconoce los modos de articulación "aspirados en la apariencia" $(h a)$, "aspirados fuertes" ( $r r a)$, "aspirados toscos" (ja, za) , "soplados" $(f a)$ y "silbados" (cha, sa).

- González de Valdés anticipa al final de la introducción de la Ortopeia una serie de características fundamentales de la voz -De Brosses las denomina "modificaciones de la voz"-, que retomará al final de su obra: (i) naturaleza, (ii) espíritu, (iii) cualidad, (iv) cantidad, (v) acento, (vi) declamación y (vii) canto.

La naturaleza, espíritu, qualidad, quantidad, acento, declamacion, y canto de la voz se distinguen por el simple sonido de ella: la naturaleza en ser animal ó inanimado: el espíritu ó respiración y la qualidad consiste en ser grueso, corpulento, delgado, áspero, ó suave, bronco, ronco, ó sordo, dulce, agradable, \&c. la quantidad en la mayor ó menor detencion de tiempo: y el acento en el ascenso ó descenso, esto es, en lo agudo ó grave del sonido, ó en lo masó menos agudo, mas ó menos grave segun segun el diametro mayor ó menor del canal de la voz. De lo qual y de la declamacion tratarémos por menor al fin en el capítulo de las sílabas, como tambien de la rapidez y mezcla de los sonidos en las palabras (González de Valdés 1785: 46-48).

- Dichas características, junto con otros datos fisioacústicos del habla y del canto, serán el broche final de la Ortopeia. En un capítulo titulado "Del canto y palabras que le convienen" -no anunciado en el índice e incluido en el capítulo III sobre elementos suprasegmentales- traduce literalmente un fragmento de De Brosses ${ }^{21}$. A través del autor francés cita a Ferrein (movimiento ondulatorio de las cuerdas vocales) y a la Enciclopedia ("ley de los cuerpos sonoros"): 


\begin{tabular}{|c|c|}
\hline De Brosses & GonZÁLEZ dE VALDÉS \\
\hline $\begin{array}{l}\text { Mais sur-tout la voix du chant consiste } \\
\text { dans les vibrations et la tension plus } \\
\text { grande ou moindre de la glotte. On doit } \\
\text { cette belle découverte à M. Ferrein. } \\
\text { Il est parvenu à faire entendre le } \\
\text { chant humain, et même les cris des } \\
\text { animaux, en soufflant dans les larinx } \\
\text { tirés des corps, et faisant onduler les } \\
\text { rubans membraneux des glottes. Les } \\
\text { contractions et les dilatations de ses } \\
\text { rubans en tout sens semblables à celles } \\
\text { des cordes des violons, forment avec } \\
\text { une êxtreme rapidité dans un petit } \\
\text { espace, les tons plus ou moins graves } \\
\text { du chant [...] } \\
\text { Le chant, qui ajoute au son vocal une } \\
\text { modulation toute particulière, une } \\
\text { ondulation mélodieuse, une intonation } \\
\text { beaucoup plus variée et plus étendue, } \\
\text { laquelle ne procède que par certaines } \\
\text { intervalles reglés. Les lois de ces } \\
\text { intervalles sont données par la nature: } \\
\text { elles partent toutes d'une certaine } \\
\text { principe fondamental, physique et } \\
\text { nécessaire, appellé la lois des corps } \\
\text { sonores: savoir, qu'un corp retentissant, } \\
\text { frappé d'un seul coup, fait entendre } \\
\text { non-seulement le son principal, mais } \\
\text { encore la quinte aigue de l'octave, et la } \\
\text { tierce plus aigue de la double octave; } \\
\text { que le même coup fait frêmir un outre } \\
\text { corps sonore voisin, s'il est plus grave } \\
\text { d'une quinte que le corps frappé. } \\
\text { De cette résonance des aigus, de ce } \\
\text { frémissement des graves, naissent la } \\
\text { les règles des accords, en un mot } \\
\text { tous les principes de la mélodie et de } \\
\text { l'harmonie (1) [On peut voir ce que }\end{array}$ & $\begin{array}{l}\text { Pero sobre todo la voz del canto consiste } \\
\text { en las vibraciones, y mayor ó menor } \\
\text { tension en la glotis. M. Ferrein ha } \\
\text { descubierto que las laringes y las glotis } \\
\text { separadas de los cuerpos de los animales } \\
\text { racionales é irracionales son por sí solas } \\
\text { capaces de hacer oir el canto y los gritos, } \\
\text { soplando en las laringes y haciendo } \\
\text { undular las fibras membranosas de las } \\
\text { glotis. Las contracciones y dilataciones } \\
\text { de estas fibras, semejantes en todo á } \\
\text { las contracciones y vibraciones de las } \\
\text { cuerdas de los violines, forman con } \\
\text { muchísima rapidez en un corto trecho } \\
\text { los tonos mas ó menos graves del canto } \\
\text { [... } \\
\text { El canto añade al sonido de la voz } \\
\text { una modulacion muy particular, una } \\
\text { undulacion melódica, y una entonacion } \\
\text { mucho mas variada y extensa, que } \\
\text { procede por ciertos intervalos arreglados } \\
\text { por la naturaleza misma, y provienen } \\
\text { todos de un principio determinado } \\
\text { fundamental físico y necesario, llamado } \\
\text { ley de los cuerpos sonoros. Es á saber, } \\
\text { que un cuerpo sonoro herido de un solo } \\
\text { golpe hace percibir no solo el sonido } \\
\text { principal, sino tambien la quinta aguda } \\
\text { de la octava, y la tercera mas aguda de } \\
\text { la doble octava, que el mismo golpe } \\
\text { causa por repercusion en otro cuerpo } \\
\text { sonoro cercano, si es mas grave de } \\
\text { una quinta, que el cuerpo tocado. } \\
\text { De esta resonancia de los agudos y } \\
\text { repercusion de los graves resulta la } \\
\text { progresion harmónica, el órden real y } \\
\text { verdadero de qualesquiera gammas, } \\
\text { la variedad de los modos mayor y } \\
\text { menor, las reglas de las consonancias, } \\
\text { y todos los principios de la melodía y } \\
\text { de la harmonía: como se puede ver en }\end{array}$ \\
\hline
\end{tabular}




\begin{tabular}{|l|l|}
\hline j'ai dit à cet égard dans le Dictionnaire & el Diccionario Enciclopédico sobre la \\
encyclopédique sur la manière dont & manera con que nacen sucesivamente \\
toutes les modulations majeures sont & unas de otras todas las modulaciones... \\
successivement engendrées les unes & $(1785: 215-216,225-227)$. \\
des autres par le résonance des aigus, & \\
et les modulations mineures par le \\
frémissement des graves] (1765 [1801]: \\
154-155, 160-161).
\end{tabular}

Tabla 6. Du chant et des paroles qui lui conviennent / Del canto y palabras que le convienen en De Brosses y González de Valdés

\subsubsection{Cuestiones ortográficas}

- "Descubrimiento de las letras". Para la confección de este capítulo, al menos en su primera mitad, González de Valdés traduce y, sobre todo, sintetiza la primera parte del capítulo VII de De Brosses, "De l'écriture symbolique et littérale". Ambos repasan las primeras representaciones pictóricas; mencionan a los indígenas de Oceanía y Norteamérica, egipcios y chinos como pueblos con escritura "simbólica"; aluden a la escritura "silábica"; y, por último, a la "literal" o alfabética ${ }^{22}$. Es evidente el mayor interés del autor francés por las cuestiones ortográficas, quien describe exhaustivamente los primitivos sistemas de la Patagonia, Canadá (iroqueses), México, Perú, Egipto, etc., trayendo numerosos testimonios históricos ${ }^{23}$ y anotaciones sobre los jeroglíficos egipcios.

\subsubsection{Cuestiones de pronunciación}

- González de Valdés inserta un comentario procedente de De Brosses sobre la distinta pronunciación de las lenguas vernáculas, pero en un lugar y argumentación distintos. Al asturiano le sirve para destacar la incomprensibilidad de los pueblos europeos cuando usan la lengua vehicular latina, mientras que De Brosses tan solo alude a los diferentes sistemas fonológicos:

22 Cfr. González de Valdés (1785: 48-67) y De Brosses (1765 [1801]: 271-282).

23 Sirvan de ejemplo Voyages du Baron de la Hontan, Historia de la conquista de México (Solís), Historia natural y moral de las Indias (Acosta), Historia general del Perú (Inca Garcilaso de la Vega), entre otros muchos documentos históricos. 


\begin{tabular}{|c|c|}
\hline De Brosses & GONZÁleZ DE VALDÉS \\
\hline $\begin{array}{l}\text { Nous usons en Europe des lettres } \\
\text { qu'il est impossible aux Chinois de } \\
\text { prononcer: et tous nos efforts sont } \\
\text { inutiles pour copier les inflexions des } \\
\text { Hottentots. Sans aller si loin, quelle } \\
\text { différence entre un Anglais qui fait sortir } \\
\text { toutes ses paroles en sifflant du bout des } \\
\text { lèvres, et un Florentin qui les fait toutes } \\
\text { rentrer dans le fond de sa gorge? Les } \\
\text { consonnes de l'allemand, du français, } \\
\text { et de l'espagnol, sont-elles parfaitement } \\
\text { les mêmes? Non, sans doute; et chaque } \\
\text { peuple qui veut prononcer un mot d'une } \\
\text { langue voisine, ne fait qu'employer } \\
\text { les lettres de sa propre langue qui en } \\
\text { approchent le plus, en se servant du } \\
\text { même organe, qu'il fléchit à la manière } \\
\text { de son pays (1765 [1801]: 93-94). }\end{array}$ & $\begin{array}{l}\text { Pues aunque son universalmente } \\
\text { inteligibles en la escritura, por estar } \\
\text { menos viciada; no se entienden } \\
\text { universalmente en el trato y comercio } \\
\text { verbal de unas naciones con otras: v. gr. } \\
\text { en la lengua latina la consonante } c \text { en } \\
\text { auceps se pronunciaba aukeps, ú okeps; } \\
\text { hoy se pronuncia viciosamente, segun los } \\
\text { Españoles, auzeps; segun los Franceses, } \\
\text { oseps; segun los Italianos, aucheps; \&c. } \\
\text { alterándose y desfigurándose en cada } \\
\text { nacion la pronunciacion legítima de } \\
\text { las palabras latinas con la nativa de las } \\
\text { lenguas vivas [...] } \\
\text { Cada nacion tiene sus diferentes modos } \\
\text { de articular. Sin salir de Europa, ni de las } \\
\text { lenguas vivas de ella escritas con unos } \\
\text { mismos caractéres, iquánta diferencia } \\
\text { hay entre un Ingles, que silvando forma } \\
\text { en la extremidad de sus labios todas } \\
\text { sus palabras, y un Florentin que las } \\
\text { forma todas al principio de su garganta? } \\
\text { Tenemos en Europa articulacion que } \\
\text { no pueden formar los Chinos: y todos } \\
\text { nuestros esfuerzos son inútiles para } \\
\text { copiar las inflexîones de los Hotentotes, } \\
\text { pueblos de África en la Cafrería... } \\
\text { (1785: 96-100). }\end{array}$ \\
\hline
\end{tabular}

Tabla 7. Diferentes sistemas fonológicos de las lenguas

(y repercusiones para su pronunciación latina)

- En ciertas ocasiones, como en la descripción del sonido /a/, comparten autoridades latinas: Plutarco y Lipsio ${ }^{24}$. Es posible que González de Valdés haya empleado aquí a De Brosses para inspirarse en sus fuentes, aunque habitualmente maneja con soltura e independencia las lecturas clásicas. 
- Se hace eco, además, de la división del canal de la voz en tres tramos (o vocales) para el hebreo, el cual no tiene letras propias para tales sonidos, sino diacríticos añadidos a las consonantes ${ }^{25}$.

A través de estos tres subapartados, se ha comprobado la utilización que hace González de Valdés de su libro de cabecera en la redacción de la Ortopeia. La huella de De Brosses es fácilmente detectable en la introducción $\mathrm{y}$ en las cuestiones sobre fonética general, aspectos para los que necesita información adicional. Secundario es su empleo en las cuestiones ortográficas (sintetiza enormemente sus anotaciones sobre historia de la escritura) y mucho más puntuales son las ocasiones en que acude a él para anotar alguna pronunciación concreta.

\section{CONCLUSIONES}

A lo largo de estas páginas se ha ofrecido al lector una serie de pautas clave para la interpretación doctrinal e historiográfica de la Ortopeia universal y se ha dado respuesta a los tres objetivos fijados inicialmente: (a) dónde se ubica dentro de la tradición ortológica española (en lo que a información articulatoria sobre la lengua española se refiere), (b) en qué consiste su originalidad e hibridismo metodológicos, y (c) de qué manera introduce las nociones ilustradas sobre la formación mecánica de la voz. Si esta obra de González de Valdés merece ocupar un lugar destacado entre los textos canónicos en la historia de la fonética española (y por ende, un lugar decisivo en su propia producción), es por los dos últimos aspectos antes que por el primero. Efectivamente, se ha visto cómo las indicaciones articulatorias que ofrece para el español no alcanzan la meticulosidad de la tradición sordomudística (piénsese en Hervás y Panduro), sino que se sitúan dentro del promedio de otras gramáticas y ortografías de la época.

Una de las principales aportaciones de este texto es la recepción temprana de las nociones ilustradas sobre fonética general, al menos, anterior a la que hasta ahora los estudiosos adjudicaban para la tradición hispánica. Se ha insistido una y otra vez en la importancia de la obra de Sicilia (su repercusión en Bello, en la Academia y en otros muchos autores a lo largo 
de los siglos XIX y XX). Cabría entonces reconocer también que ciertas teorías sobre la formación de la voz -las más sencillas-son introducidas 42 años antes por el profesor asturiano, a través de la adaptación y traducción de fragmentos de la obra de De Brosses. Es este uno de los méritos de la Ortopeia, y el cotejo presentado en este trabajo da cuenta de ello. González de Valdés dedica una extensión considerable a las cuestiones sobre fonética general y se nutre de la información técnica aunque divulgativa del Traité de la formation méchanique des langues (1765). Llega incluso a traducir un capítulo entero ("Del canto y palabras que le convienen", de más de veinte páginas, no anunciado en el índice), por lo que bien puede considerarse el traductor español de la obra francesa. En la recepción del texto, el asturiano opta en ocasiones por adaptarlo y ajustarlo a la realidad de la lengua española (por ejemplo, al no reconocer la vocal nasal en la división del tracto vocal).

Junto con la introducción de estas nociones generales, la Ortopeia propone una sistemática contrastividad -lenguas clásicas y vernáculas- y una insistencia clave en la separación del plano gráfico del fónico. Tales contenidos le confieren originalidad e hibridismo, de ahí que esta obra sobrepase las convenciones del género ortológico de la época. Su heterodoxia puede resumirse a partir de la exégesis - que se propone a continuación- del título del libro, cuidadosamente pensado por el autor: Ortopeia universal ó Arte de pronunciar. Según los principios físicos elementales de que depende el modo de articular, hablar, leer, y escribir bien en todos los lenguajes, por sonidos simples y compuestos, demostrados con exemplos visibles en las letras y silabas de palabras escritas en lengua Griega, Latina, y Española.

"Ortopeia". Son varias las ocasiones en que alude a esta disciplina practicada en la Antigüedad clásica: "en Griego ó $\rho \theta$ oÉ $\varepsilon \varepsilon ı \alpha$ es la arreglada y legítima expresion del sonido en qualquier estado y diferencia en todas las palabras, y estilos del lenguaje"(1785: 25). Establece los dos niveles de análisis, segmental y suprasegmental: "la qual [Ortopeia] enseña la disposicion ó postura de todos los instrumentos ó partes de la boca, de que nos servimos para formar las articulaciones de los sonidos simples representados en letras vocales solas, ó en las consonantes inseparables de las vocales; y las de los compuestos separados por sílabas, esto es, la pronunciacion elemental y acentual segun Lipsio" (1785: 98). En su opinión, la materia enseñada por el phonascos ya no se practica (al menos en nuestro país, tal y como denuncia), de ahí que su título rinda homenaje a la disciplina.

"Bien". El concepto normativo de su tratado se aplica en especial a las pronunciaciones clásicas: "bien" parece significar "conforme al uso de los clásicos'; se trata de corregir los errores que los hispanohablantes cometen cuando hablan latín y griego antes que los que manifiestan en su propia 
lengua ( $\tan$ solo se han detectado algunas observaciones aisladas sobre la pronunciación de las palabras terminadas en $-d$ ).

"Universal" / "todas las lenguas". Al igual que el tratado de De Brosses, el autor persigue la intención de describir los mecanismos generales de pronunciación de todas las lenguas. Dispone dicha información en la introducción y en capítulo final titulado "Del canto y palabras que le convienen". En los apartados sobre elementos segmentales y suprasegmentales alude a un gran número de lenguas: latín, griego, español, francés, inglés, italiano, etc.

"Principios físicos elementales". Trata de formar al maestro en nociones básicas sobre fisiología y acústica del habla. La información es superficial y nunca llega a la descripción minuciosa manifestada por autores como Beauzée o la Enciclopedia: con una síntesis de los datos aportados por De Brosses es suficiente.

"Sonidos demostrados con exemplos visibles de las letras". Y, por último, se constata desde el propio título su interés por abrir una brecha entre ambos planos.

\section{REFERENCIAS BIBLIOGRÁFICAS}

\section{Fuentes primarias}

Bonet, Juan Pablo. 1620. Redvction de las letras y arte para enseñar a hablar los mvdos. Madrid: Francisco Abarca Angulo.

De Brosses, Charles. 1765 [1801]. Traité de la formation méchanique des langues et des principes pysiques de l'étymologie. Paris: Terrelongue.

DoDART, DenIs. 1703. Mémoire sur les causes de la voix de l'homme et de se différents tons. S.l.

Encyclopédie ou Dictionnaire raisonné des Sciences, des Arts et des Métiers, par une société de gens de lettres. 1751-1780. Diderot y D'Alembert (eds.). Paris: Le Breton/David/Durand.

Encyclopédie méthodique: Grammaire et littérature. 1782-1786. Beauzée y Marmonte (eds.). Paris \& Liège: Panckoucke \& Plomteux.

GonzÁlez Valdés, Juan Antonio. 1779. Silabario teórico-práctico dividido en tres listas. [Lengua española]. Madrid: Joaquín Ibarra.

1779. Silabario teórico-práctico dividido en tres listas. [Lengua latina]. Madrid: Joaquín Ibarra.

1785. Silabario trilingüe para aprender á leer y escribir todos los sonidos simples elementales de la lengua Española, Griega, y Latina. Madrid: Imprenta Real.

1785. Ortopeia universal o Arte de pronunciar. Madrid: Joaquín Ibarra.

[pseudónimo Antonio Casero]. 1785. Problema resuelto en favor del mejor método de enseñar á leer en todas las lenguas. Madrid: Joaquín Ibarra. 
[pseudónimo Antonio Casero]. 1785. Verdadero método de enseñar a leer y a escribir los sonidos simples y complexos, explicado brevemente en verso. Madrid: Imprenta Real.

Harduin, Alexandre-Xavier. 1755. Remarques diverses sur la prononciation et sur l'orthographe. Paris: Prault.

1760. Dissertation sur les voyelles et les consonnes. Paris: Lambert.

HeRvÁs Y PANDURO, LoRENZO. 1795. Escuela española de sordomudos ó arte para enseñarles á escribir y hablar el idioma español. Madrid: Imprenta Real.

Martínez Gómez Gayoso, Benito. 1743 [1769]. Gramática de la lengua castellana. Madrid: Gabriel Ramírez.

Martínez de Noboa, Antonio. 1839. Nueva gramática de la lengua castellana. Madrid: Eusebio Aguado.

Sebastián, Miguel. 1619. Orthographia y orthologia. Zaragoza: Juan de Larumbe.

Sicilia, Mariano José. 1827-1828 [1832]. Lecciones elementales de ortología y prosodia. Madrid: Imprenta Real.

Torío de la Riva, Torcuato. 1804. Ortología y diálogos de caligrafía, aritmética, gramática y ortografia castellana. Madrid: viuda de Ibarra.

Fuentes secundarias

Abercrombie, DAVID. 1948. "Forgotten phoneticians". Transations of the Philological Society, $1-34$.

Alonso, Amado. 1967-1969. De la pronunciación medieval a la moderna en español. Madrid: Gredos [2 vols.].

Auroux, Sylvain. 1979. La sémiotique des encyclopédistes. Paris: Payot.

2000."Charles de Brosses". Corpus de textes linguistiques fondamentaux (CTLF).

Lyon: ENS [en línea]. Disponible en: http://ctlf.ens-lyon.fr/n_fiche.asp?num=5102 [consulta 7/7/2014].

Auroux, Sylvain y Louis Jean Calvet. 1973. "De la phonétique à l'apprentissage de la lecture : La théorie des sons du langage au XVIIIe siècle". La linguistique 9: 71-88.

Battaner Moro, Elena. 2009a. "La investigación sobre ortografía, fonética y fonología en la tradición lingüística española". En José María García Martín (dir.). Estudios de historiografia lingüistica, pp. 27-45. Cádiz: Servicio de Publicaciones de la Universidad de Cádiz.

2009b. "Escuela española de sordomudos de Lorenzo Hervás y Panduro". Reseña de Escuela española de sordomudos. La gramática de la lengua de signos en su contexto interlingüistico y pedagógico (2008, edición de Ángel Herrero). Beiträge zur Geschichte der Sprachwissenschaft 19: 161-166.

2012. "Lenguas y signos. Influencia francesa en la Escuela Española de Sordomudos de Lorenzo Hervás y Panduro". En Elena Battaner et al. (eds.). Historiografía lingüística: líneas actuales de investigación, vol. I, pp. 179-193. Münster: Nodus Publikationen.

Battaner Moro, Elena y Francesca Dovetto. 2013. "La educación lingüística de personas sordas en el siglo XVIII". Romanistik in Geschichte und Gegenwart 19/1: 77-95.

BEAL, JoAn. 1999. English pronunciation in the Eighteenth century. Oxford: Clarendon Press.

Bouton, Charles P. 1984. Discours physique du langage. Genèse et histoire de la Neurolinguistique. Paris: Klincksieck.

Esteve Serrano, Abraham. 1982. Estudios de teoría ortográfica del español. Murcia: Universidad de Murcia.

FourniER, JEAN-Marie. 2007a. "La notion d'unité sonore dans les grammaires françaises des $17^{\mathrm{e}}$ et $18^{\mathrm{e}}$ siècles". Studies in the History of the Language Sciences 112: 120-130. 
2007b. "La généralité dans les théories du son à l'âge classique”. Histoire Épistémologie Langage [Histoire des théories du son] 29: 85-103.

García Folgado, Ma . José. 2005. La gramática española y su enseñanza en la segunda mitad del siglo XVIII y principios del XIX (1768-1815). Valencia: Universidad de Valencia [Tesis Doctoral].

Gómez Asencio, José J. 1981. Gramática y categorías verbales en la tradición española (1771-1847). Salamanca: Ediciones Universidad de Salamanca.

1985. Subclases de palabras en la tradición española (1771-1847). Salamanca: Ediciones Universidad de Salamanca.

2004. "Una gramática rara: la de Don Agustín Muñoz Álvarez (1793 y 1799)". En C. Corrales Zumbado et al. (eds.). Actas del IV Congreso Internacional de la SEHL, vol I, pp. 653-668. Madrid: Arco/Libros.

2009 [1996]. "José Antonio González de Valdés". En Harro Stammerjohann (ed.). Lexicon Grammaticorum. Tübingen: Max Niemeyer, pp. 551-552.

Hunt, Frederick Vinton. 1978. Origins in Acoustics: the science of sound from antiquity to the age of Newton. New Haven \& London: Yale UniversityPress.

Infantes, Víctor y Ana Martínez Pereira. 2003. De las primeras letras. Cartillas españolas para enseñar a leer del siglo XVII y XVIII. Salamanca: Ediciones Universidad de Salamanca [2 vols.].

Koerner, E. F. KonRad. 1995. "History and Historiography of Phonetics. A state-of-the-art account". Professing linguistic historiography, pp. 171-202. Amsterdam: John Benjamins.

LAVER, JOHN. 1978. "The concept of articulatorysettings: anshistoricalsurvey". Historiographia Linguistica 4: 1-14.

LÁzaro Carreter, Fernando. 1985 [1949]. Las ideas lingüisticas en España durante el siglo XVIII. Barcelona: Crítica.

Mac NAmee, Terence. 1984. "Normativity in 18th century discourse on speech". Journal of Communication Disorders 17: 407-423.

Martínez AlCALde, Ma . José. 2010. La fijación ortográfica del español: norma y argumento historiográfico. Bern: Peter Lang.

2012. "Observaciones sobre pronunciación en ortografías castellanas de autores valencianos (siglo XVIII)". En Adela García Valle et al. (eds.). Fablar bien e tan mesurado. Veinticinco años de investigación diacrónica en Valencia. Estudios ofrecidos a María Teresa Echenique Elizondo en conmemoración de su cátedra, pp. 115-136. Valencia/ Neuchâtel: Tirant Humanidades.

2013. "Las relaciones entre código oral y código escrito en la historia del español. Ortografía y prosodia". En M $\mathrm{M}^{\mathrm{a}}$. Teresa Echenique Elizondo et al. (eds.). Historia de la pronunciación de la lengua castellana, pp. 295-336. Valencia/Neuchâtel: Tirant Humanidades.

2014. "De gramma, gramática: el incierto lugar de las letras". En Ma . Luisa Calero Vaquera et al. (eds.). Métodos y resultados actuales en Historiografía de la Lingüística, vol. II, pp. 496-510. Münster: Nodus Publikationen.

Poch Olivé, Dolors. 1999. "Lorenzo Hervás y Panduro y la reeducación de sordomudos. Contribución al estudio de un capítulo de la historia de la lingüística española". En Jesús Fernández González et al. (eds.). Lingüistica para el siglo XXI. Actas del III Congreso de Lingüistica General, pp. 1299-1308. Salamanca: Ediciones Universidad de Salamanca.

QuiJada VAn den Berghe, Carmen. 2014. "La Ortopeia Universal (1785) en el programa educativo de González Valdés". En María Luisa Calero et al. (eds.). Métodos y resultados actuales en Historiografia de la Lingüistica, vol. II, pp. 595-606. Münster: Nodus Publikationen. 
En prensa. "Contribución de los tratados de ortología del siglo XIX a la historia de la fonética y la fonología españolas". Revista argentina de historiografía lingüistica 6/2.

Rey, Christophe. 2007. "Nicolas Beauzée: la clé inexploitée de la phonétique française". Studies in the History of the Langage Sciences 112: 197-211.

2011. Nicolas Beauzée, précurseur de la phonétique: dans "L'encyclopédie" de Diderot et d'Alembert, "La grammaire générale" et "L'encyclopédie méthodique" de Panckoucke. Paris: H. Champion.

Satorre Grau, F. Javier y Mª. Luisa Viejo Sánchez. 2013. “Ortología”. En Mª Teresa Echenique Elizondo et al. (eds.). Historia de la pronunciación de la lengua castellana, pp. 337-379. Valencia: Tirant Humanidades.

Swiggers, Pierre. 1984a. Les conceptions linguistiques des Encyclopédistes. Étude sur la constitution d'une théorie de la grammaire au siècle des Lumières. Heidelberg: Groos.

1984b."Les fondements de la théorie phonétique des encyclopédistes". Zeitschrift für Phonetik, Sprachwissenschaft un Kommunikations-Forschung 37: 348-354.

Wollock, Jefrerey. 1997. The Noblest Animate Motion. Speech, physiology and medicine in pre-Cartesian linguistic thought. [Studies in the History of the Language Sciences, 83]. Amsterdam/Philadelphia: John Benjamins.

Zamorano, Alfonso. 2004. El subjuntivo en la historia de la gramática española (1771-1973). Madrid: Arco/Libros. 